\title{
Design, Participação e Engajamento Como Estratégias para Qualificar Relações de Uso em Abordagens de Design no Âmbito do Projeto ETHOS.
}

Design, Participation, Engagement As Strategies for Qualifying Use Relationships in Design Approaches linked to ETHOS Project.

EVERLING, Marli T. Doutora em Design; Universidade da Região de Joinville - UNIVILLE marli.everling@gmail.com

THEIS, Mara Rubia; Mestranda em Design; Universidade da Região de Joinville - UNIVILLE marubiat@yahoo.com.br

SANTOS, Filipe Mesquita dos; Mestrando em Design; Universidade da Região de Joinville UNIVILLE

filipee.mesquita@gmail.com

CECYN, Leonardo Calixto Colin; Mestrando em Design; Universidade da Região de Joinville UNIVILLE

Leonardo-Colin@hotmail.com

RODRIGUES, Rafaela; Mestranda em Design; Universidade da Região de Joinville - UNIVILLE rafaela.arq1@gmail.com

LaFRONT, Ronald; Graduando em Design; Universidade da Região de Joinville - UNIVILLE r.tibab1980@gmail.com

\section{Resumo}

A proposta visa discutir conceitos relacionados ao novo design, incluindo participação no desenvolvimento de soluções de problemas no âmbito do projeto ETHOS. A metodologia envolveu revisão de literatura (especialmente o escopo teórico produzido por Sanders em colaboração com outros autores no que se refere a mudança do papel do designer em processos de participação, cocriação e co-design) e conexões destes conceitos relacionados ao projeto ETHOS. Os resultados explicitam o entendimento destes conceitos no âmbito do projeto ETHOS.

Palavras Chave: design centrado no humano; design e relações de uso; participação. 


\begin{abstract}
The proposal aims the discussion of concepts related to new design, including participation in developing solutions in ETHOS projetct context. The methodology is driven to literature review (mainly theoretical approaches produced by Sanders with other authors regarding designer role changing in the role in participation, cocreation and co-design processes) and the connection of these concepts to the project Ethos. The results show up the meaning of these concepts in the ETHOS realm.
\end{abstract}

Keywords: human centered design; user relationship; participation

\title{
Introdução ${ }^{1}$
}

A caracterização dos modos de saber, de conhecer e métodos de pesquisa que são específicos para a Área dos Desenhos (Design) era discutida já na década de 60 (século XX) no Britânico Royal College of Art in General Education. O assunto tem desdobramentos desde então, Cross (2004) avançou esta distinção por meio do texto 'Designerly Ways of Knowing' propondo um raciocínio comparativo entre as Áreas das Ciências e Humanidades com a Área dos Desenhos. Para o autor o modo de cognição peculiar desta área é o concreto/icônico; sua natureza é construtiva, normativa e criativa; apóia-se na síntese de padrões e na manipulação de códigos nãoverbais da cultura material facilitando o modo de pensar construtivo e focado na solução. Para o autor esta área do conhecimento não confia tanto em modos verbais, numéricos e literários de pensar e comunicar: "Isto fica evidente no uso que o desenhador faz de modelos e códigos gráficos, como imagens, diagramas e esboços que ajudam não só o pensamento como também a comunicação de ideias e instruções a outros” (EVERLING, 2011 apud CROSS, 2004, p. 19).

Nesta discussão o autor já defendia princípios (designer precisam ser habilitados para produzir soluções novas e inesperadas, tolerar a incerteza, trabalhar com informação incompleta, aplicar imaginação e antecipação criativa, empregar grafismos e outras formas de modelagem para resolver problemas práticos) destacados na atualidade, pela revisão do conceito de design proposto World Design Organization (WDO) em 2016.

Figura 1: informações centrais da Definição de Design World Design Organization

\begin{tabular}{ll}
\hline O que é & $\begin{array}{l}\text { Processo de resolução de problemas orientado para a inovação; } \\
\text { Preenche a lacuna entre 'o que é' e o 'que é possível'. }\end{array}$ \\
\hline Objetivo & $\begin{array}{l}\text { Utilizar a criatividade para resolver problemas e co-criar soluções (e ampliar a qualidade de vida) } \\
\text { com a intenção de melhorar um produto, sistema, serviço, experiência ou negócio. }\end{array}$ \\
\hline \multirow{2}{*}{ Essência } & $\begin{array}{l}\text { Fornece um caminho mais otimista para vislumbrar o futuro por meio da ressignificação de problemas } \\
\text { em oportunidades. Situa o humano no centro do processo. Possui profunda compreensão das } \\
\text { necessidades do usuário por meio da empatia e aplicam um processo pragmático de processo de } \\
\text { solução de problemas centrado no usuário para projetar produtos, sistemas serviços e experiências. }\end{array}$ \\
\hline Como? & $\begin{array}{l}\text { Interliga inovação, tecnologia, pesquisa, negócios e consumidores no intuito de atribuir novos valores } \\
\text { nas esferas econômica, social e ambiental. }\end{array}$ \\
\hline
\end{tabular}

Fonte: Adaptado da definição de design da World Design organization (WEB, 2016)

A compreensão do design está ampliada enquanto processo estratégico de resolução de problemas que contempla a participação de todas as pessoas (designer e não designers) desde a investigação e co-criar soluções para que gerem impactos mais abrangentes, a favor do bem estar de todos e da qualidade de vida. A ressignificação de problemas em oportunidades necessita de

\footnotetext{
${ }^{1}$ Os conceitos discutidos ao longo da introdução são centrais para a contextulização do projeto ETHOS.
} 
planejamento coletivo e participativo, com atuação clara de todos participantes, mantendo o humano no centro do processo, constituindo relações empáticas e visão holística, com objetivo de gerar novos valores nas esferas econômica, social e ambiental.

A estruturação da discussão compreende a descrição e análise dos papéis do usuário, do pesquisador e do designer em processos participativos, de co-design ou co-criação; a importância da empatia e escolhas de ferramentas adequadas considerando os problemas de design a serem afrontados; reflexões sobre como promover o engajamento na prospecção/criação ficcional do futuro. Posteriormente conceitos apresentados são conectados a algumas das pesquisa do projeto ETHOS como: (1) o planejamento estratégico de ferramentas para desenvolver a inovação educacional com a abordagem do design participativo; (2) o engajamento do usuário a partir de processos de hospitalização infantil; (3) uso de gambiarras e uso prescrito versus uso real como estratégia para acessar o conhecimento subjetivo das pessoas nas soluções que criam no cotidiano;

\section{Compreensão dos papéis do participante, do pesquisador e do designer em processos participativos, de co-design ou co-criação.}

Para Sanders e Stappers (2008) os desafios de design, hoje, são mais amplos que desenvolver produtos para usuários. Para os autores pessoas, comunidades e cultura estão conectadas e os indivíduos estão informados de uma maneira que seria inimaginável em outros tempos tecnológicos; o vertiginoso ciclo de mudanças e desafios (incluindo a sobrevivência humana e a manutenção do meio ambiente) requer que se desenhe prospectivamente para experiências futuras. O meio acadêmico tem acompanhado as discussões e transformado (figura 02) a oferta de disciplinas tradicionais do design (orientadas para o desenvolvimento de produtos) para disciplinas emergentes de design orientadas para o propósito.

Figura 2: Comparativo da evolução das disciplinas tradicionais em disciplinas emergentes de design

\begin{tabular}{|c|c|c|c|}
\hline \multicolumn{2}{|c|}{ disciplinas tradicionais do design focam em produtos... } & \multicolumn{2}{|c|}{ disciplinas emergentes de design visam o propósito... } \\
\hline $\begin{array}{l}\text { Design e comunicação visual } \\
\text { Design de espaços interiores } \\
\text { Design da informação }\end{array}$ & $\begin{array}{l}\text { Design de produtos } \\
\text { Arquitetura } \\
\text { Planejamento }\end{array}$ & $\begin{array}{l}\text { design para sustentabilidade } \\
\text { design para serviços } \\
\text { design para transformar }\end{array}$ & $\begin{array}{l}\text { design para experiência } \\
\text { design para emoção } \\
\text { design para interação }\end{array}$ \\
\hline
\end{tabular}

Fonte: adaptado de Sanders e Stappers (2008)

Este movimento de transformação no meio acadêmico, impacta nos papéis desempenhados pelas pessoas envolvidas nos processos de Design Centrado no Usuário (DCU) e no Design Centrado no Humano (DCH), conforme demonstrado figura abaixo. 
Figura 3: Papéis do Usuário, pesquisador e designer nas abordagens do DCU e no Co-design, DCH

\begin{tabular}{|c|c|c|c|}
\hline Abordagem & Usuário & Pesquisador & Designer \\
\hline $\begin{array}{l}\text { Clássica do } \\
\text { design centrado } \\
\text { no usuário }\end{array}$ & $\begin{array}{l}\text { Objeto passivo de } \\
\text { estudo }\end{array}$ & $\begin{array}{l}\text { Traz o conhecimento de teorias e } \\
\text { desenvolve mais conhecimento a } \\
\text { partir de observações e entrevistas }\end{array}$ & $\begin{array}{l}\text { O designer recebe as informações e } \\
\text { por meio do seu conhecimento } \\
\text { tecnológico e pensamento criativo } \\
\text { gera conceitos e ideias }\end{array}$ \\
\hline $\begin{array}{l}\text { Co-design } \\
\text { DCH } \\
\text { Participativo } \\
\text { Co-criação }\end{array}$ & $\begin{array}{l}\text { É especialista da } \\
\text { experiência e tem } \\
\text { um papel } \\
\text { significativo no na } \\
\text { produção de } \\
\text { informações, } \\
\text { sessões generativas } \\
\text { e conceitos de } \\
\text { desenvolvimento }\end{array}$ & $\begin{array}{l}\text { Dá suporte ao usuário (por meio de } \\
\text { ferramentas de ideação e expressão) } \\
\text { para, que o usuário/especialista por } \\
\text { meio de sua experiência gere } \\
\text { insights. Colabora junto com o } \\
\text { designer nas ferramentas para } \\
\text { ideação porque as habilidades de } \\
\text { design são relevantes no } \\
\text { desenvolvimento das ferramentas }\end{array}$ & $\begin{array}{l}\text { Possui um papel crítico em dar } \\
\text { formas às ideias. } \\
\text { Colabora junto com o pesquisador } \\
\text { nas ferramentas para ideação porque } \\
\text { as habilidades de design são } \\
\text { relevantes no desenvolvimento das } \\
\text { ferramentas (o designer e o } \\
\text { pesquisador podem ser a mesma } \\
\text { pessoa) }\end{array}$ \\
\hline
\end{tabular}

Fonte: adaptado de Sanders e Stappers (2008)

Acompanhando as transições da abordagem de design centrado no usuário (DCU) para o design centrado no ser humano (HCD), Lee (2012) compara transformações e a ampliação do nível de participação do usuário que inicialmente fornecia informação para o designer, passou a ser envolvido na co-criação e reflexões apoiadas no potencial criativo para abordagem em desafios de impacto social.

Figura 4: Transição do DCU e no Co-design, DCH

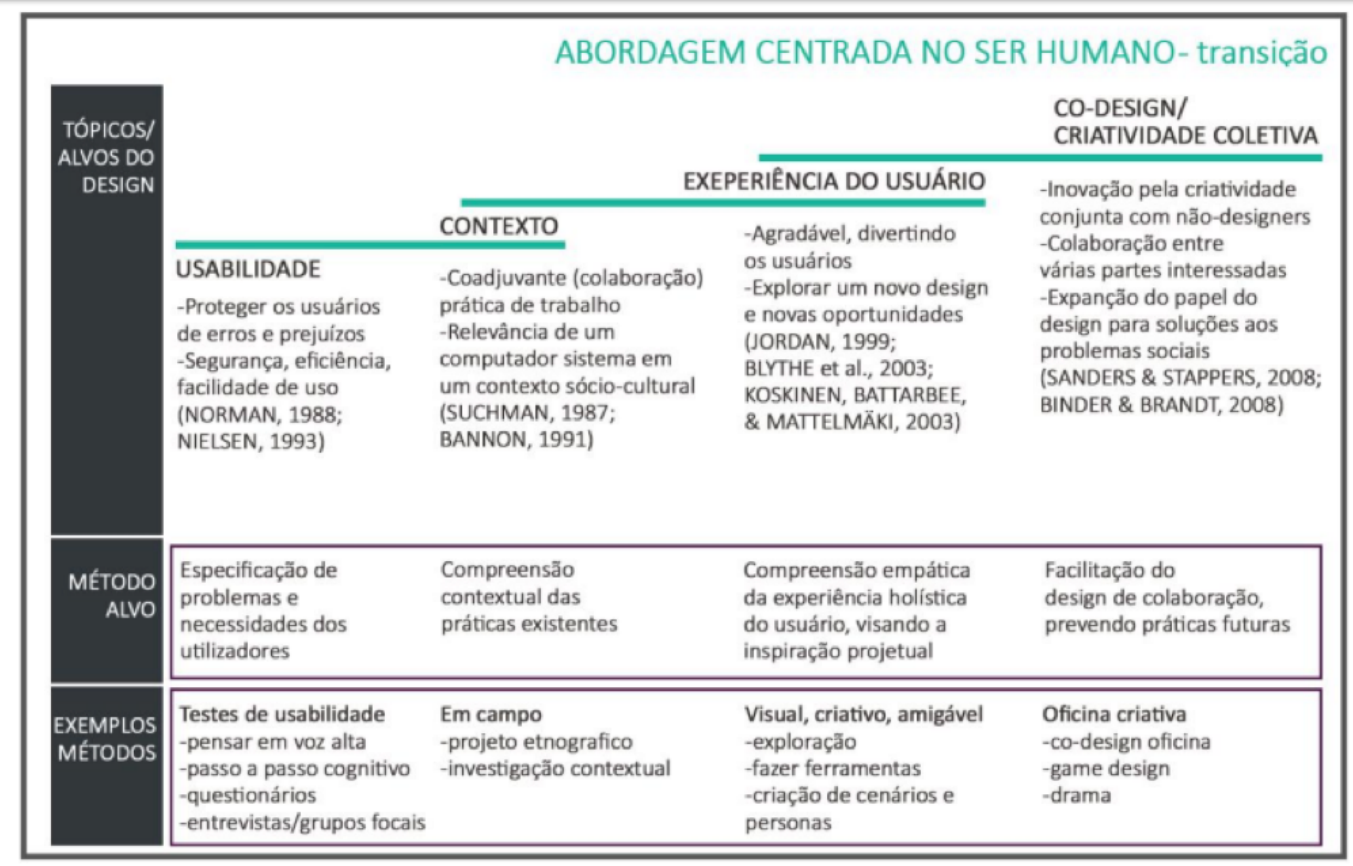

Fonte: Lee (2012, p. 20) traduzido por Ganske (2016, p.62)

Diante deste cenário, a compreensão inicial de Design e Relações de Uso que orienta o projeto ETHOS (Ações de Pesquisa Técnico-Científica Orientadas para o Design e Relações de Uso) e a abordagem deste artigo está destacada na figura 5. O problema que direciona as atividades 
pode ser resumido como: que ações podem ser desenvolvidas pelo projeto ETHOS para contribuir com a produção e a disseminação do conhecimento orientado para design e relações de uso abrangendo, prioritariamente, o cenário social, público/urbano e de indústria/serviços?

Figura 5: Concepção de Design e Relações de Uso que orienta as ações do projeto ETHOS

Design
A concepção de design incorpora a ideia de $\begin{aligned} & \text { Os conteúdos associados a 'Relações de Uso' compreendem a } \\ & \text { interação usuário/objeto/meio ambiente com ênfase na dimensão } \\ & \text { processos metodológicos centrados no humano } \\ & \text { orientados para: (1) a qualificação do cotidiano por } \\ & \text { meimana, fundamentos associados à cognição e aprendizagem, } \\ & \text { mexperiência de uso, comportamento do usuário, usabilidade, } \\ & \text { serviços; (2) a co-criação de soluções; e (3) a } \\ & \text { atuação do designer como catalisador para a criação } \\ & \text { coletiva em uma prescrito e real) e abordagens do novo design (como design } \\ & \text { participação abrangendo a inovação social e a } \\ & \text { sustentabilidade. }\end{aligned}$

Fonte: Projeto ETHOS (EVERLING, 2017)

Esses conceitos de design e relações de uso aplicados em projetos e situações reais, ampliam reflexões e discussões em torno dos processos aplicados na proposição de soluções inovadoras desenvolvidas com o usuário, o exercício e experiência com métodos e ferramentas do design centrados no humano. Nestas abordagens a colaboração (a participação e a co-criação), o respeito e a empatia são premissas, bem como a observação do contexto e das necessidades visando diminuir impactos negativos e ampliar possibilidade de benefícios para todos.

Assim como as novas concepções de design, o projeto ETHOS possui como figura o humano e, como pano de fundo, os processos que permitem a sustentabilidade da vida, não apenas a humana (respeitando assim a área de concentração do Programa de Mestrado Profissional em Design da Universidade da Região de Joinville/PPGDesign-Univille ao qual o projeto ETHOS é vinculado). Sua intenção é beneficiar pessoas, comunidades e humanidade (mais do que gerar lucratividade), e oportunizar a participação de todos os envolvidos no contexto do problema, personalizando métodos de interação pautados no relacionamento com respeito e abertura para cocriação na experimentação. Neste sentido, os tópico abordados na sequência (com base no pensamento de Sanders por favorecer a experiência das pessoas, sua participação e a subjetividade) como participação, empatia, engajamento, levantamento de soluções vernaculares podem contribuir para o desenvolvimento de projetos mais conectados com os anseios dos usuários em um nível mais profundo, bem como, contribuir com modos de abordagem que facilitem a atuação do designer como mediador.

\section{A Abordagem do Design Centrado no Humano.}

Em propostas de soluções com abordagem de Design Centrado no Humano (DCH), seja no âmbito de produtos, serviços ou sistemas, Sanders (2002) enfatiza a necessidade de mudança de atitude de 'projetar para os usuários' em direção a 'projetar com os usuários' promovendo uma experiência empática, que requer a disponibilidade de colocar-se no lugar do outro em profundidade e conectar a mente, o coração e o corpo. O movimento em equipe deve ser orientado por um conjunto de ferramentas que estimulem o potencial criativo individual promovendo o relacionamento horizontal, a participação de todos (especialmente dos não-designers).

Segundo a Ideo (2009), em seu toolkit personalizado de ferramentas denominado Human Centered Design/HCD (traduzido para Design Centrado no Humano/DCH) processos de design pautados nesta abordagem deve considerar três fases: (1) ouvir (hear/human), (2) criar (create /create) e (3) implementar (deliver/design) com o desafio em propor soluções desejáveis, 


\section{GAMPI $_{\text {plural }}{ }^{17}$}

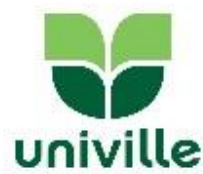

praticáveis e viáveis, alternando o pensamento concreto e abstrato (figura 6), para orientar a coleta dados mais significativos com maior eficácia e eficiência, analisar e delinear objetivos e manter o foco na criação de soluções inovadoras.

Figura 6: Processo estratégico de Design Centrado no Humano (HCD)

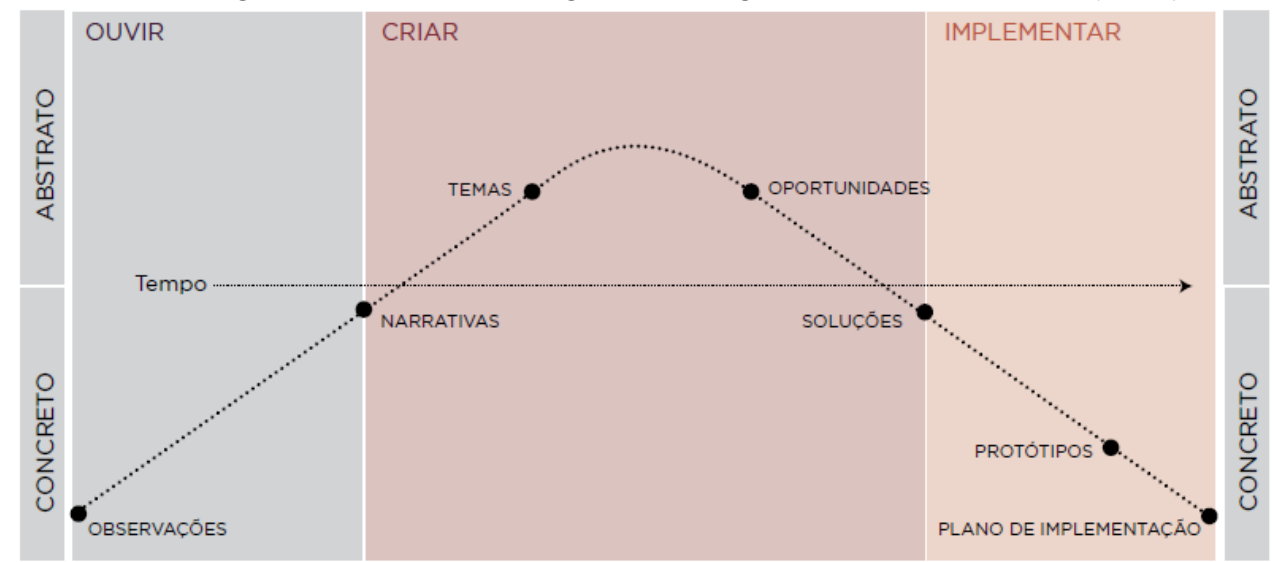

Fonte: IDEO (2009)

Nesta abordagem, processos de co-criação e/ou participativos tornam-se mais flexíveis e dinâmicos, ampliando a visão de que organizações são constituídas por estruturas físicas, mas, sua essência é o intangível formada pelos valores (crenças, hábitos, cultura) das pessoas e comportamentos. Essas variáveis determinam se a conexão entre as pessoas, gerará comunicação fluída ou pontos de tensão provenientes também da cultura organizacional.

Em uma discussão sobre os diferentes tipos inovação, Liem e Sanders (2013) consideram positivamente a abordagem do $\mathrm{DCH}$ como estratégia de colaboração aplicada aos desafios e projetos de design desenvolvidas entre academia e empresas, oportunizando aos estudantes a prática em desafios reais, uma pseudo-experiência profissional de consultoria.

Esta abordagem parte do entendimento que a experiência é individual e única, dependendo do contexto, situação e influências por diferentes circunstâncias (tempo, lugar, valores culturais, regras, contexto externo social). Para as pessoas, o valor está relacionado a utilidade; os significados social, espiritual e emocional (a serem consideradas na interação com os produtos ou serviços, ou na solução de problemas cotidiano dos envolvidos), requerem preparação cuidadosa de cada uma das etapas do projeto de pesquisa com a formulação de ferramentas personalizadas. A aproximação com o usuário final e a vivência empática junto a ele permitem o aprofundamento das estratégias, mantendo o foco nas pessoas, e preparando o próximo passo da pesquisa; a cada etapa devem ser propostas análises e sínteses dos dados, bem como, devem ser selecionadas ferramentas visuais que tornem as informações simples e visíveis a todos.

O processo de cocriação tem o desafio de integrar a todas as pessoas na equipe, em um relacionamento horizontal que resulte em cooperação e requer uma preparação de ferramentas (toolkit), personalizadas para delinear os objetivos, mapear a empresa e clientes, revelar os problemas, identificar soluções e possibilidades, bem como, incentivar novas ideias e a criatividade; neste cenário as ferramentas são mais analógicas, de síntese, visualização de padrões e visuais. 


\section{Aplicabilidade da Participação e do Design Centrado no Humano em um contexto de Educação Tecnológico}

O Projeto 'Criar, desenhar e modelar nos processos de design de moda', objetiva a redução da complexidade no processo de aprendizagem dos conhecimentos de desenho, modelagem e ergonomia nos cursos de design de moda e vestuário, a partir da organização dos métodos autorais de "Cânones Estruturais para o Desenho de Moda" e da "Modelagem Cartesiana para Artigos do Vestuário", estimulando a criatividade e a inovação. Sua meta é estruturar o material didático de apoio a aprendizagem (no contexto do Instituto Federal de Educação, Ciência e Tecnologia de Santa Catarina - IFSC, Campus Jaraguá do Sul) conectando conhecimentos associados ao desenho e a modelagem de artigos do vestuário a partir da compreensão do corpo humano para potencializar o processo criativo. A pesquisa instigou algumas sondagens e observações em campo junto aos colegas educadores, profissionais de moda para as quais foram utilizadas abordagens de design participativo, design centrado no humano e cocriação em busca de aprimorar os métodos de ensino e da aprendizagem dos processos criativos de design de moda sob a ótica dos estudantes (vivência empática) e sua aplicabilidade no campo profissional. O resultado esperado é a disponibilização do material didático para o corpo discente e docente do IFSC.

Para delinear a problematização, foi sugerido o exercício da empatia com os estudantes durante o processo de aprendizagem; o desafio proposto foi acompanhar algumas aulas relacionadas ao desenho, modelagem e projeto integradores para exercitar a observação dos conteúdos e atividades (abril e maio do corrente ano). A ferramenta escolhida foi a "fly on the wall", com a qual o pesquisador permanece como observador na sala de aula sem interferência ou interação alguma, para a vivência foi preparada uma ficha de observação para fazer os registros e considerações. Esta atividade oportunizou o exercício da empatia com os estudantes, a observação de outro ângulo, desde o espaço físico, a organização dos materiais, a expectativa dos professores; as perspectivas dos estudantes em sala de aula e a disputa de sua atenção com as tecnologias, comunicação digital em seus aparelhos de telefone e computador. Outro ponto registrado foi o anseio dos estudantes em poder fazer as práticas dos desenhos e modelagem em sala junto do professor, momento no qual conseguem instrução para suas dúvidas e correções das atividades.

No mesmo período, foi preparado um 'canvas de inovação educacional' (figura 7), uma ferramenta que reúne várias perguntas para que cada participante reflita sobre as variáveis a serem consideradas no entorno do projeto e permite a identificação do problema em profundidade, resultando em diretrizes para o planejamento estratégico de uma proposta de valor para solução e métricas do impacto social do desafio. 
Figura 7: Ferramenta Canvas de Inovação Educacional

CANVAS
Titulo do seu projeto: Criar, Desen
2. QUAL É O PROJETO?
SUA COMPREENSÃO
-Aproximar linguagem
de Desenho e
Modelagem em prol da
Criatividade + imersão
-Linguagem Visual
-Corpo humano
-Simplificar a aprendizagem
-tornar comum/intuitivo
Conectar, integrador?
Estudante=usuário,
E Book 3.o

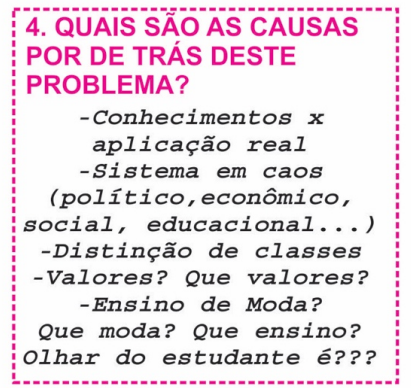

\section{COMO VOCÊ REDEFINIRIA}

ESTE PROBLEMA?

Como criar linguagens facilitadoras para o aprendizado

de desenho e modelagem? Pensar. Reflexão. Indissociável.

Valorizar o potencial? Interdisciplinar, como? Como harmonizar... desenho modelagem e corpo..

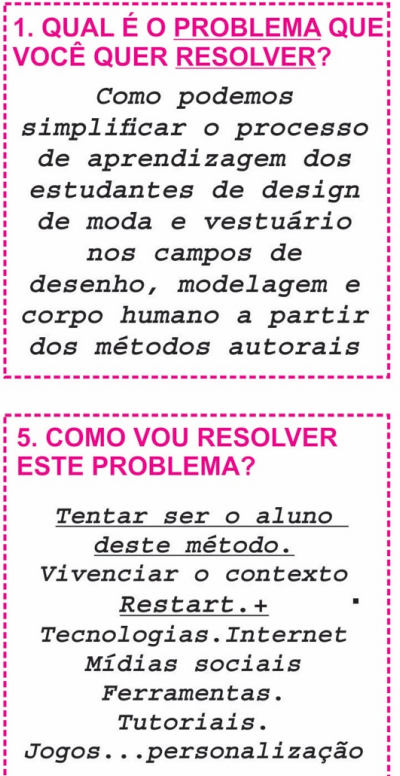

Tentar ser o aluno deste método. vivenciar o contexto Restart.+

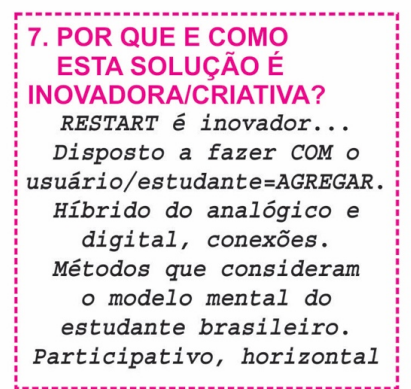

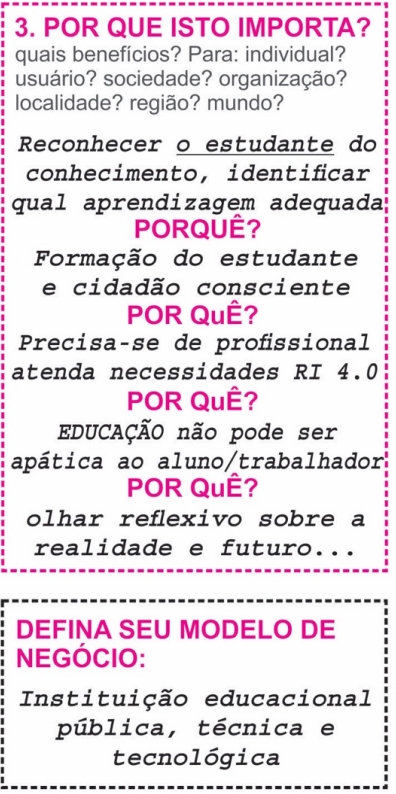

8. COMO SERÁ O SEU PROTÓTIPO PARA FAZER A IDEIA SAIR DO PAPEL? FAZER AGORA: Desenho analógico do ebook.

Sumário, sub capítulos

Ir a campo e conversar. Fazer com colegas e com estudantes. com Empatia.

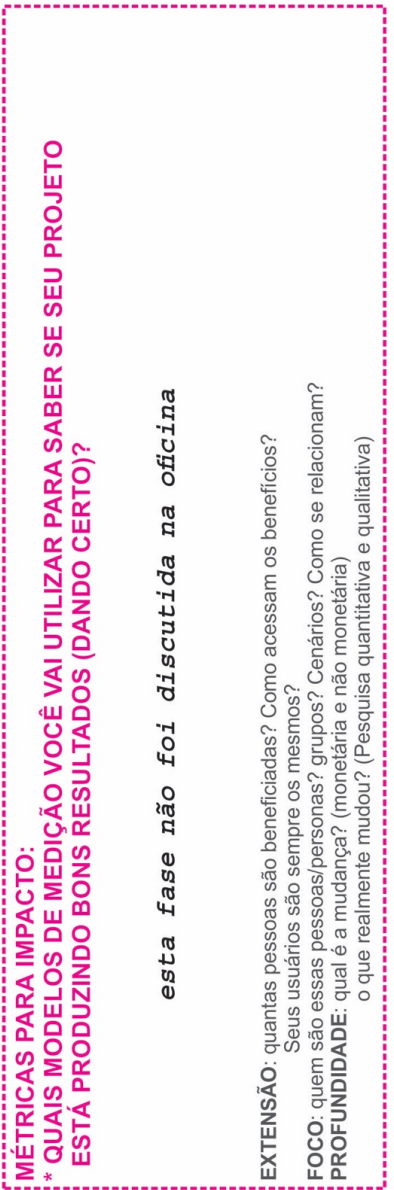

Fonte: adaptado pelo autor (Escola de Design Thinking, 2016)

A oficina iniciou com a contextualização do desafio a ser tratado pela pesquisa relacionada a criar, desenhar e modelar no processo criativo de design de moda, em síntese adicionada a pergunta inicial que orienta o projeto foi compartilhada (número 1 do canvas) para ser o guia da reflexão sobre como podemos simplificar o processo de aprendizagem dos estudantes de design de moda e vestuário nos campos de desenho, modelagem e corpo humano a partir dos métodos autorais potencializando a criatividade e inovação. Na sequência os participantes foram orientados a refletir sobre as perguntas (por que, como, quem, quando, onde, dentre outras) orientadoras da ferramentas canvas, tinham um tempo para reflexão e escrita (post it médios, instigar a objetividade) com a ferramenta brainwriting (cada participante responde a pergunta em silêncio por escrito em post it) e posteriormente compartilha oralmente para o grupo de forma sucinta. As atividades contribuíram com a reflexão sobre o momento atual de transformações e inquietações, além de validar hipóteses relacionadas a proposta da pesquisa com a participação de colegas educadores para $o$ aprimoramento do desenvolvimento do material didático conectando os métodos autorais de desenho e modelagem alinhados ao modelo mental do estudante.

A escola está sendo instigada a repensar-se enquanto espaço de aprendizado que considere desafios e situações locais e reais para experimentar os métodos de pesquisa e habilidades, iniciando o estudante na compreensão dos sistemas de crenças e valores que serão aprimorados ao 
longo da vida. Diante desse movimento de busca por novas formas de educação, convívio, trabalho, produção e consumo. O novo espírito tem como propósito estabelecer relações mais benéficas para todos e para o ecossistema, novas formas de pensar, sentir, agir, produzir e criar valor, fatores que têm afetado o campo educacional. Neste sentido o campo educacional pode ser o espaço propício para estimular o desenvolvimento do potencial criativo de todas as pessoas e proporcionar experiências centradas no humano.

\section{O Engajamento e Design for Change como Estratégias para Transformação.}

Compreende-se que a participação é uma vertente do design para integrar os participantes à equipe de pesquisa, segundo Sanders (2002), o usuário deixa de ser apenas 'o usuário' e passa a ser membro partícipe da equipe de pesquisa, fator que gera o sentimento de pertencimento, comprometimento e engajamento dos participantes. Aponta que o design participativo como uma mudança de atitude nas atividades de design. Essa mudança leva o ato de projetar para usuários a projetar com usuários, conduzindo o design a um novo momento chamado como Post Design ou Pós Design. É comum que, em meio ao design participativo não existam hierarquias ou regras a serem seguidas, tendo o pesquisador como uma ponte entre o partícipe e a equipe técnica. Assim, os partícipes percebem que podem influenciar uma rede, e utilizam desta rede quando engajados a uma causa para conquistar o que desejam.

A discussão de Sanders (2002) intitulada "Abordagens centradas no usuário para projetos participativos" esclarece o papel do designer enquanto mediador do processo e elucida como acessar a experiência por meio de abordagens participativas, ouvindo, interpretando, vendo, observando, descobrindo, sentindo, apreciando sonhos e permitindo a experiência do usuário.

Abraas, Maloney-Krichmar e Preece (2004), consideram que o envolvimento dos usuários no projeto é executado de tal forma que se tornam co-designers, levantando questões que a equipe de design jamais imaginaria para o projeto sem a contribuição direta da experiência do usuário.

De acordo com Sanders e Stappers (2014) engajamento está contido dentro de um dos movimentos do design que abrangem três níveis de alcance em uma escala semi-circular, na qual cada linha corresponde a um anel ou camada (figura 8). O primeiro anel compreende o mundo real onde estão situados a experiência do usuário, o design de intervenção e o design de serviço. No segundo anel está situado o futuro próximo, englobando o design crítico, a interação incorporada e o design social. No terceiro anel o único campo abordado é o design de ficção, que é encontrado na fatia do design de engajamento em um cenário no qual os designers (especialistas da área) auxiliam a compreensão dos cidadãos sobre os métodos propostos, estimulando sua participação para a melhoria das soluções desenvolvidas. 
Figura 8 - Movimentos do design

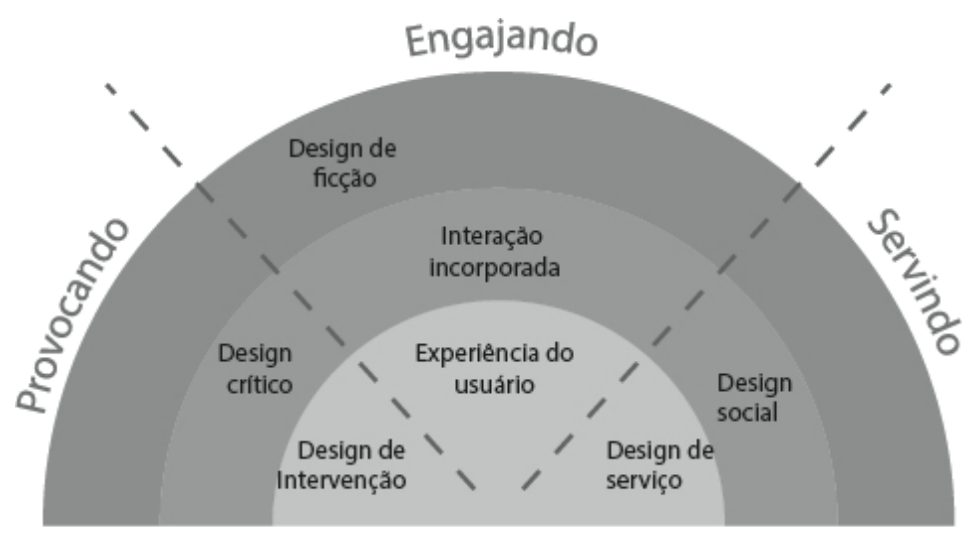

Movimentos do Design

Fonte: Adaptado pelos autores de acordo com Sanders (2014)

Dentre os movimentos do design abordados durante a pesquisa, o design de ficção elucida a interação entre o futuro previsível e o futuro abstrato, o que possibilita a participação de pessoas de todas as faixas etárias, inclusive as crianças que trazem em sua essência a imaginação sem fronteiras, a pureza do coração e atitudes sinceras, estes aspectos de importância para consolidar relacionamentos empáticos e colaborativos. Sob essa percepção, surge na Índia em 2006 um movimento global usando estrutura similar aos processos de design participativo denominado 'Design for Change' (criado e disseminado por Kiran Bir Sethi); esta proposta envolve crianças e jovens com o objetivo de possibilitar a expressão e implementação de suas ideias para transformar a realidade que os rodeia, contribuir com o entendimento de que elas podem ajudar a modificar o mundo como protagonistas de suas histórias e de sua comunidade, uma responsabilidade de todos os que requerem o exercício da cidadania. Para facilitar a compreensão das crianças e o diálogo, a metodologia é apresentada como um toolkit em quatro fases (figura 9), apoiado em verbos: (1) sentir; (2) imaginar; (3) fazer; (4) compartilhar; orientações de atividades em cada etapa da fase.

Figura 9 - Etapas do Design for Change

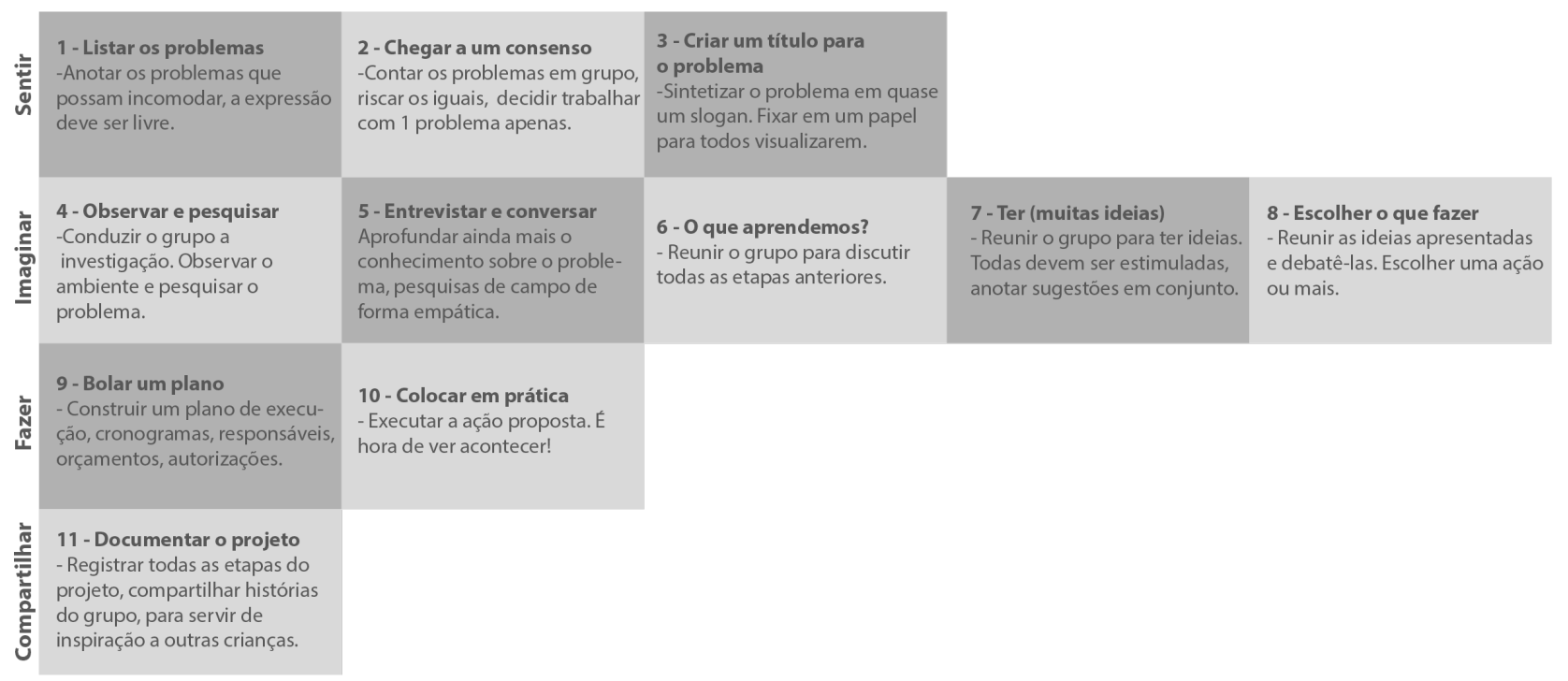

Fonte: Adaptado pelos autores de acordo com toolkit do Design for Change (web). 
As quatro fases propostas pela metodologia do Design for Change, compreende onze etapas: (a) sentir - listar os problemas; chegar a um consenso; criar um título para o problema; (b) imaginar - observar e pesquisar; entrevistar e conversar; o que aprendemos?; ter muitas ideias; escolher o que fazer; (c) fazer - bolar um plano; colocar em prática; (d) compartilhar - documentar o projeto.

As ferramentas do design aplicadas sob a nova ótica de perceber o que as pessoas fazem, com foco na geração de empatia entre os envolvidos no trabalho, para que possam vivenciar a experiência projetar-se no lugar do outro, fato que possibilita novas soluções de produtos, ambientes, serviços e contextos sociais, projetando soluções com as pessoas.

\section{Aplicabilidade dos Conceitos de Engajamento e do Design for Change em Processos de Hospitalização Infantil}

Pesquisas com este enfoque iniciaram em 2016 com o projeto 'Design de Superfície Aplicado no Auxílio do Tratamento do Câncer Infantil' (ver CECYN, 2016); este estudo possui forte apelo participativo com as crianças que se encontravam na ala oncológica de um hospital Infantil de Joinville; o objetivo principal do estudo de caso foi a humanização deste espaço. Tornar uma experiência de internação infantil mais prática, integradora e multidisciplinar, para que estas crianças invernadas estejam engajadas na melhoria dos espaços hospitalares, e juntos possam elencar os problemas e encontrar maneiras de solucioná-los como autoras de um mesmo projeto.

A abordagem participativa, engajamento e protagonismo (das crianças) em meio ao ambiente hospitalar é o elo entre o projeto finalizado no ano de 2016 e movimentos futuros de pesquisa já iniciados visando utilizar a experiência participativa como uma ferramenta de engajamento. Neste estudo, portanto, pretende-se que as crianças tornem-se fortes engajadores de sua causa, sendo replicadores desta ideia nos mais variados ambientes.

Os princípios do 'Design For Change' e de sua versão desenvolvida no Brasil sob o título 'Criativos da Escola' (que ressalta a importância da observação do contexto local e envolvimento das pessoas para as quais se destina a proposta), foi considerado apropriado pela intenção de promover a participação das crianças internadas para contribuírem com as experiências pessoais dos enfrentamentos diários. O toolkit será sistematizado a partir da dinâmica conduzida com as crianças hospitalizadas por meio da ferramenta de cocriação. As ferramentas prevêem a sua aplicabilidade em seu contexto com a participação em pequenos grupos, a partir do engajamento e protagonismo para resolver problemas do cotidiano.

\section{A Relevância de Olhar para o Uso Prescrito, Uso Real e Gambiarras...}

A experiência empática ou imersão na jornada do usuário é importante para que o design possa cumprir o seu papel de trazer ao mundo soluções para problemas reais, como menciona Cross (2004): é necessário entender o problema das pessoas para criar soluções para as pessoas, e estas pessoas podem ainda participar ativamente do processo, de maneira colaborativa.

Durante o processo de projetos de design com estratégias de colaboração (co-criação ou codesign) relatado por Liem e Sanders (2013), o designer pode adotar três perspectivas criativas distintas para a imersão de análise do problema, apresentadas na figura 10, e identificar o modelo mental do responsável pelo projeto. Enquanto em co-criação há um modelo mental voltado para a participação dos usuários/das pessoas como membros do grupo de trabalho, no extremo oposto, existem duas perspectivas em que o usuário é visto como objeto de estudo, seja pela abordagem do Design ou do Design Centrado no Usuário. 
Figura 10 - Perspectivas dos processos de desenvolvimento

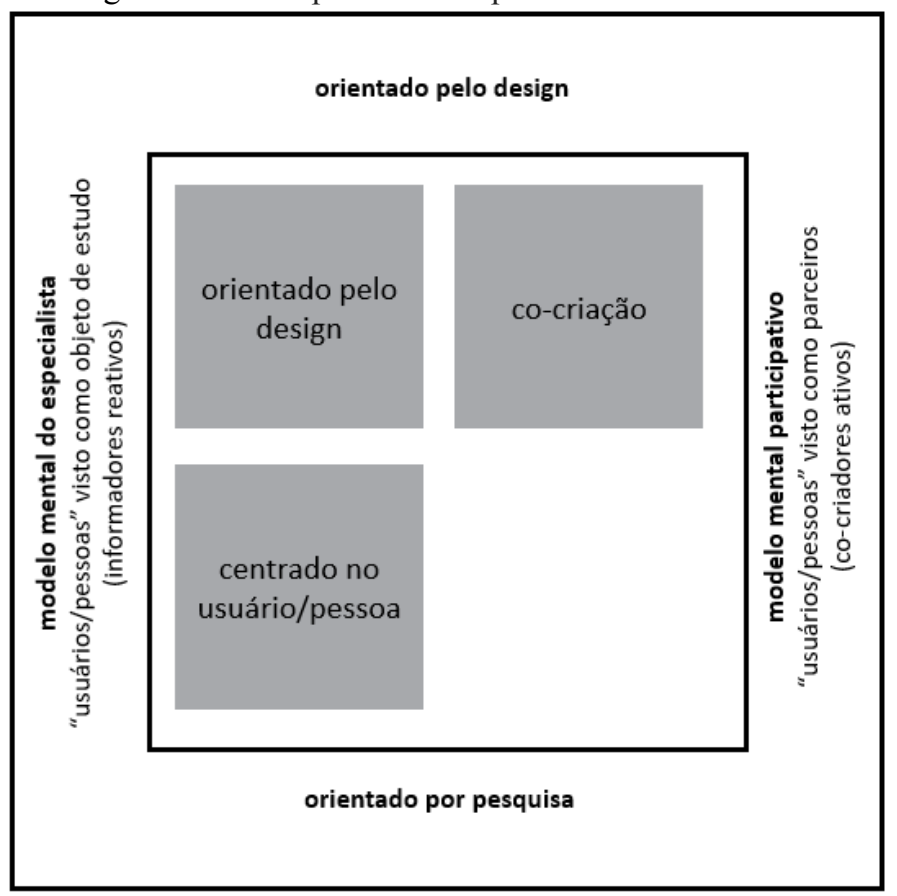

Fonte: Adaptado pelos autores de Liem e Sanders (2013)

Indiferente da perspectiva adotada na execução, projeto e análise empírica dos problemas do usuário, é importante ressaltar que o uso da solução criada é uma dimensão própria, conforme sugere Kasper (2009). O autor observa que os designers esquecem que o uso na 'vida real' pode ser diferente do uso estimado inicialmente, na criação da solução. Uma vez que, tanto o processo de Co-criação quanto a prática de empatia pelo viés do Design Centrado no Usuário estão imersos em situações controladas ou situacionais, a 'vida real' impõe aos usuários novas variáveis que podem alterar drasticamente as relações de uso com o produto criado.

Enquanto o Uso Prescrito orienta o desenvolvimento do projeto cujo esforço visa auxiliar o usuário a solucionar algum problema previamente estabelecido, o Uso Real surge do confronto da solução criada com os obstáculos impostos pelo ambiente real, assim, podem surgir novas aplicações para a solução criada a partir do desvio da função inicialmente proposta por Kasper (2009), conforme as situações relacionadas ao uso de produtos (figura 11).

Figura 11 - Novas aplicações criadas a partir do desvio da função inicial

\begin{tabular}{l|l|l|l}
\hline Deslocamento & Adaptação & Extensão & Desvio de função \\
\hline $\begin{array}{l}\text { uso imprevisto de um } \\
\text { artefato, quando não altera } \\
\text { sua composição, apenas } \\
\text { sua aplicabilidade. }\end{array}$ & $\begin{array}{l}\text { parcialmente o usuário altera } \\
\text { como por exemplo o o } \\
\text { prolongamento de de do anções. } \\
\text { ferramenta. }\end{array}$ & $\begin{array}{l}\text { para que se acumule mais } \\
\text { nano tem nada em comum } \\
\text { com sua função inicial. }\end{array}$ \\
\hline
\end{tabular}




\section{Aplicabilidade de Conceitos de Uso Prescrito, Uso Real, Gambiarras em Desafios Relacionados ao Consumo de Água}

Para os designers é importante observar que, os desdobramentos feitos pelos usuários para um produto, as conhecidas "gambiarras", podem revelar novos problemas e novas soluções. Para exemplificar, podemos utilizar o modo como as pessoas lidam com a água no dia a dia. É de fácil observação que a maioria das pessoas concordam com a importância da utilização racional da água, uma vez que o recurso é essencial para a vida e a sua ausência causa inúmeros desconfortos. Neste caso, o 'uso prescrito' é conhecido pelo usuário, porém, não é praticado como 'uso real'. Assim, o desperdício de água pode ser visto em várias situações como: limpeza de calçadas, banhos demorados, água corrente durante execução de atividades que não a utilizam (lavar louças, escovar os dentes), entre outros.

Embora os produtos envolvidos na disponibilização da água para o usuário, do reservatório até a sua aplicação final, tenham sido projetados para locais em que há água disponível, é importante observar que as pessoas adaptam seu comportamento e sua maneira de lidar com estes produtos em uma situação adversa aquela em que os produtos foram idealizados, como em locais naturalmente áridos, em que a água é sempre escassa ou tenham períodos de seca recorrentes, e locais em que possuem água regularmente, mas por uma situação climática atípica ou por interferência humana na qualidade da água, tornam o recurso temporariamente escasso (NOVA ESCOLA, 2010). Nestes cenários, surgem novas aplicações como: utilização de diversos recipientes como reservatórios extras de água, aplicação de arejadores - produto que mistura ar com água - para dar volume a água, redutores de pressão nas tubulações, reutilização de água para tarefas domésticas, entre outros.

A empatia aplicada ao contexto dos usuários de água nas duas situações, ou o desenvolvimento de soluções para a escassez de água pela abordagem do design ou de pesquisas, tendo as pessoas como objetos de análise ou como participantes do processo, podem sim contribuir para a criação de soluções eficazes para o problema. No entanto, é importante considerar que, a 'vida real' abrange infinitas situações que não podem ser observadas no período de desenvolvimento da solução, ou mesmo previstas, deixando margem para que os usuários criem novas aplicações ou adaptações para a solução lançada. Desta forma, é importante que os responsáveis pelo desenvolvimento das soluções estejam atento ao problema, aos cenários de aplicação e aos usuários antes, durante e depois do processo de criação, e, mais do que isso, considerem as soluções criadas pelos próprios usuários (especialistas de suas necessidades) que muitas vezes revelam situações e necessidades latentes que podem ser incorporadas aos projetos de design. 


\section{Considerações Finais}

No âmbito do projeto ETHOS o Design é compreendido como estratégia de re-significação e resolução de problemas com a participação de pessoas para as quais se direciona a proposta dos projetos, mantendo o humano no centro do processo. Nesta perspectiva, pessoas, comunidades e cultura estão conectadas, os indivíduos são especialistas da realidade a ser transformada e o designer é mediador que suporta o processo de fruição da problematização, da criatividade e das soluções seja no cenário social, público/urbano e de indústria/serviços. Esta abordagem requer a colaboração, participação, respeito e a empatia bem como a observação e contínua adequação ao contexto, as relações e ao cenário real da situação que está sendo abordada.

Os processos participativos de cocriação partem do respeito e da empatia com todos as pessoas pertencentes ao desafio, a observação em profundidade e do contexto no qual está inserido, isto influenciará o planejamento estratégico das ações e do movimento da equipe que devem ser orientados por um conjunto de ferramentas que estimule o potencial criativo individual promovendo o relacionamento horizontal, flexível e dinâmico, visando a participação de todos (especialmente dos não-designers), conectando a mente, o coração e o corpo.

A formação do designer está em transformação: da orientação de profissionais focados no desenvolvimento de produtos para o usuário, para um mediador com visão holística emergente do novo design orientado para 'o propósito', que projeta com o usuário para beneficiar pessoas e comunidades mais do que gerar lucratividade. Trata-se de um novo modelo mental a ser exercitado, que inclui geração de valor mais focada na utilidade e nos significados 'social', 'espiritual' e 'emocional' que permitirá inovação com cocriação; esta dinâmica também integra o usuário ao processo de design, aproximando empresas e estudantes e gerando uma nova consciência e impactos sociais positivos.

O exercício de observar o contexto educacional instigou algumas sondagens e observações em campo junto aos educadores, profissionais de moda com as abordagens de design participativo centrado no humano e da cocriação. Foram identificadas evidências de que há necessidade de desenvolver materiais didáticos mais adequados ao modelo mental do estudante, com a sua participação. Outra percepção é a transformação do papel do professor em mentor, orientador e facilitador do processo de aprendizagem com o uso de novas metodologias e ferramentas. $\mathrm{O}$ engajamento desenvolve o sentimento de pertencimento e desperta a motivação para contribuir com a formação de uma geração que está inquieta com o atual sistema social, cultural e educacional, mas com sonhos para cocriar e compartilhar um futuro melhor para todos.

Em relação a hospitalização infantil, a aplicação de conceitos ligados ao design participativo foram significativos para o engajamento pessoal das crianças possibilitando a autoria de soluções para seus enfrentamentos diários.

Os desafios relacionados ao consumo de água solicitam o olhar do usuário como gerador ativo de novas soluções, a partir do confronto do 'uso prescrito' e do 'uso real' frente às situações cotidianas que não podem ser previamente percebidas durante o momento empático. Cabe ao designer, nesta situação observar os usuários/pessoas durante o processo de desenvolvimento, bem como, após o lançamento, seja produto, serviço ou processo, uma vez que a 'vida real' impõe desafios permanentes, tornando necessária a revisão constante de 'causa' e 'solução' dos problemas.

O projeto ETHOS tem sua essência a participação, o engajamento, o design centrado no humano e a empatia. Neste sentido os estudos relatados ao longo deste artigo procuram evidenciar como estes conceitos foram conectados com desafios oriundos do contexto educacional, de hospitalização infantil e de desafios relacionados ao comportamento 'real' de consumo de água. Esta abordagem requer ênfase nos aspectos de preparação das ferramentas no intuito de orientar as dinâmicas (equilibrando aspectos subjetivos e objetivos) e ao mesmo tempo, disponibilizar a sensibilidade, estabelecer laços de confiança, promover a participação, acessar e compreender, da 
melhor maneira, valores e aspectos subjetivos, comportamentais e culturais dos participantes.

\section{Referências}

ABRAS, C; MALONEY-KRICHMAR, D.; PREECE, J. User-Centered Design. In: Bainbridge, W. Encyclopedia of Human-Computer Interaction. Thousand Oaks: Sag Publications, 2004.

BECKER, Howard S. Falando da Sociedade: ensaios sobre as diferentes maneiras de representar o social. Rio de Janeiro, RJ: Jorge Zahar Ed., 2009.

CECYN, Leonardo Calixto Colin. Design de superfície aplicado no auxílio do tratamento do câncer infantil. 2016. 102 folhas. Trabalho de Conclusão de Curso - Universidade da Região de Joinville.

CIPINIUK, Alberto. Design: o livro dos porquês. Rio de Janeiro, RJ: Editora PUC-RIO, 2014

ESCOLA DE DESIGN THINKING. 2016. Ebook inovação social. Disponível em: $<$ https://rdstationstatic.s3.amazonaws.com/cms\%2Ffiles\%2F10183\%2F1445025989E-book_InovacaoSocial.pdf >. Acesso em: 15.jun. 2016.

IDEO. Human Centered Design Toolkit. 2009. PDF. Disponível em <www.ideo.com/work/human-centered-designtoolkit> Acesso em: 10 mar. 2017.

KASPER, Christian Pierre. Além da função, o uso. Arcos Design 5 - Dezembro de 2009. Rio de Janeiro: PPD ESDI/UERJ. Páginas de 18 a 23.

LIEM, André; SANDERS, Elizabeth B.-N.. Human-centred Design Workshops in Collaborative Strategic Design Projects: An educational and professional comparison. Design and Technology Education: an International Journal, [S.1.], v. 18, n. 1, mar. 2013. ISSN 1360-1431. Disponível em: <https://ojs.lboro.ac.uk/DATE/article/view/1801>. Acessado: 05. july 2017.

NOVA ESCOLA. A água é um recurso natural esgotável. 2010. Disponível em: https://novaescola.org.br/conteudo/1142/a-agua-e-um-recurso-natural-esgotavel. Acesso em: 20 jul. 2017.

This is a preprint of an article submitted for consideration in CoDesign, Taylor \& Francis, March 2008. CoDesign is available online at http://journalsonline.tandf.co.uk 1/16. http://www.maketools.com/articlespapers/CoCreation_Sanders_Stappers_08_preprint.pdf

SANDERS; Elizabeth B.; STAPPERS Pieter Jan. Co-creation and the new landscapes of design. 2008. Disponível em http://www.maketools.com/articles-papers/CoCreation_Sanders_Stappers_08_preprint.pdf. Acesso em 17 jul. 2017

SANDERS, Elizabeth B.-N. From user-centered to participatory design approaches. In: FRASCARA, J. (Ed) Design and the social sciences, Taylor \& Francis Books Limited, 2002.

SANDERS , Elizabeth B.-N; STAPPERS, Piter Jan. Probes, toolkits and prototypes: three approaches to making in codesigning. 2014.2 Disponível em: http://www.tandfonline.com/doi/abs/10.1080/15710882.2014.888183?journalCode=ncdn20. Acesso em 16 jul. 2017.

\section{Site Criativos da Escola: Design for Change Brasil. Disponível em:}

<http://criativosdaescola.com.br/> Acesso em: 17 de julho de 2017. 